\title{
The epidemiology of the sea lice, Caligus elongatus Nordmann, in marine aquaculture of Atlantic salmon, Salmo salar L., in Scotland
}

C W Revie', G Gettinby², J W Treasurer ${ }^{3}$ and G H Rae ${ }^{4}$

${ }^{1}$ Department of Computer and Information Sciences, University of Strathclyde, Richmond Street, Glasgow G1 1XH

2 Department of Statistics and Modelling Science, University of Strathclyde, Glasgow G1 1XH

${ }^{3}$ Marine Harvest (Scotland) Ltd, Lochailort, Inverness-shire PH38 4LZ

${ }^{4}$ Scottish Quality Salmon, Durn, Isla Road, Perth PH2 7HG

Correspondence C W Revie, Department of Computer and Information Sciences, University of Strathclyde, Richmond Street, Glasgow G1 1XH. Email crawford@dis.strath.ac.uk

\begin{abstract}
Although Caligus elongatus is one of two major species of sea lice that parasitise farmed salmon, its epidemiology has not been extensively studied. In this communication, the abundances of the adult stage of $C$. elongatus in salmon populations from 33 farms on the west of Scotland between 1997 and 2000 have been analysed for evidence of seasonal and annual patterns. The findings indicate that the pattern of $C$. elongatus is remarkably consistent from year to year, and directly opposed to that reported for Lepeophtheirus salmonis the other major species In particular, adult infestations rapidly increase from the start of July each year, and are more prevalent on salmon in the first year of production than the second year. Treatment is seen to have an effect on levels of infestation but it is not clear why this species should have significantly lower levels of abundance in the second year of production. There is also evidence that fallowing has no effect on abundance. Strategic management programmes for the control of sea lice on salmon farms, which are increasingly effective in controlling $L$. salmonis, may also have to give greater consideration to $C$. elongatus.
\end{abstract}




\section{Introduction}

Two species of caligid copepods account for almost all sea lice infestations on farmed salmonids in North Atlantic waters. The species of major interest has been Lepeophtheirus salmonis (Krøyer, 1837) and the epidemiology of these ectoparasites has been widely studied in the search for a better understanding of how infestations can be reduced in fish populations (Bron, Sommerville, Wootten \& Rae 1993a,b; Pike \& Wadsworth 1998; Costelloe, Costelloe, O'Donohoe, Coghlan \& O'Connor 1999). The species Caligus elongatus (Nordmann, 1832) has received considerably less attention, yet it also is an important source of infestation in salmonid fish stocks. Because $C$. elongatus are not host specific they transfer between hosts (Wootten, Smith \& Needham 1982; Neilson, Perry, Scott \& Valerio 1987; Bruno \& Stone 1990; Stuart 1990). Consequently, the species is one of the most common parasitic copepods in British marine waters (Kabata 1979), parasitising over eighty species of fish including gadoids, such as cod (Karlsbakk, Otterlei, Hoie \& Nylund 2001), scianids (Landsberg, Vermeer, Richards \& Perry 1991), herring (MacKenzie \& Morrison 1989) and pollack (Shaw \& Opitz 1996).

C. elongatus is smaller in size than L. salmonis and causes skin lesions when abundant. It is widely distributed on the body surface of the host (Wootten et al. 1982, Johnson \& Albright 1991) but is relatively well developed for free-swimming and may leave the host's body (Neilson et al. 1987, Pike 1989). Similar to other caligid copepods, the lifecycle comprises 2 nauplus stages, 1 copepodid and 4 chalimus (Piasecki 1996). The adult stage, which forms the focus of the analysis presented here, is described by Kabata (1979). The adult stages of both species are highly sexual dimorphic though the size difference between sexes is much less prominent for $C$. elongatus.

Early reports on the epizootiology of $C$. elongatus on farmed salmon in Scotland were described by Wootten et al. (1982), Bron et al. (1993) and Grant \& Treasurer (1993). In Canada, early studies by Hogans \& Trudeau (1989) reported the species to be a significant parasite, accounting for over $95 \%$ of copepods recorded. Early reports of C. elongatus infestations in Norway (Bristow \& Berland 1991) and in Ireland (Jackson \& Minchin 1992) noted the presence of this species though infestations were not deemed to be significant to 
health. Indeed in a more recent study in Norway (Wallace 1998) C. elongatus accounted for only $2 \%$ of all mobile stages recovered over a two year period. Tully (1989) suggested that there were 3 generations between July and January with up to 6 in a year, while Hogans \& Trudeau (1989) estimated that there were 4 to 8 generations per year on the Canadian Atlantic coast.

The objective of the work reported here has been to clearly identify whether there are distinctive patterns of $C$. elongatus infestations on farmed Atlantic salmon (Salmo salar L.) in Scotland. In particular, are these epidemiological patterns related to seasonal, annual and management factors; and are they different to those reported for $L$. salmonis which is widely recognised as an important constraint to the health and efficient production of farmed salmon? This communication reports the seasonal pattern and year-to-year variation of the abundance of $C$. elongatus adults observed on salmon farmed in commercial sites throughout Scotland for the period 1997 to 2000 . This provides evidence that the species not only occurs at low levels of lice per fish compared to its companion species $L$. salmonis but also exhibits a remarkably consistent abundance behaviour depending on season and year of production.

\section{Materials and methods}

\section{Data set}

The lice infestation patterns reported in this paper were collected within a production environment from 33 salmon farms spread along the west coast of Scotland. Over the period 1997 to 2000 lice counts were typically carried out on a weekly basis from April to October, and every second week throughout the rest of the year. At each sample point, on each farm, between four and six cages were sampled as described in Treasurer and Pope (2000). Each sample record included staged and sexed counts for the L. salmonis species. However, in the case of $C$. elongatus only post-chalimus stages were recorded and it is the mean abundance of these adult lice, defined as the average infestation per fish (Bush, Lafferty, Lotz \& Shostak 1997), which is reported here. Each cage mean was based on five randomly sampled fish, and so the weekly abundance levels reported for any site are based on 
between 20 to 30 fish. In total over 64,000 fish were sampled over the four year period reported here. All sites were stocked with a single year class of fish and operated a production cycle lasting up to two calendar years. At each site for each calendar year, sea lice abundance levels are considered as individual site-years, and are referred to as either first or second production years.

\section{Statistical methods and data management}

Methods of analysis have largely focused on providing descriptive summary statistics of adult lice levels over time and aggregated according to site-years in the first or second year of production. Mean weekly abundances of lice on fish are provided and where appropriate standard errors are given. Statistical comparisons between data sets have been undertaken using paired and independent t-tests at the $5 \%$ significance level. In addition the associated 95\% confidence intervals $(\mathrm{Cl})$ are given for mean differences. Correlation analysis have been undertaken using Pearson's coefficient and its associated 95\% confidence interval. The data were managed as a set of relational tables in Access 2000 (Microsoft) while the analysis and graphical output were obtained using a combination of Excel 2000 (Microsoft) and Statistica 5.5 (StatSoft Inc.)

\section{Results}

For the years 1997 to 2000 a total of 32,090 counts of $C$. elongatus adult infestations per fish were reported as weekly measurements obtained from fish in their first year of production and spanning a total of 58 site-years. Similar counts were examined for 32,070 fish from 44 siteyears in their second year of production. The clear relative increase in intensity of sampling in the second year arises because abundance levels of $L$. salmonis, the species of major commercial concern in Scotland, are known to be higher in this period (Revie et al. 2002).

\section{Seasonal abundance}

Figure 1 shows the weekly abundances of adults pooled across the 4 years and averaged according to week of the first or second production year. For fish in their first year of production, there is a distinctive pattern. Following the first few weeks of the year, the adult 
lice counts oscillate at levels of around 1 louse per fish until mid-year. After week 26, lice numbers steadily increase to between 5 and 10 lice per fish before starting to fall back around week 37 and returning to an average of 1 to 2 lice per fish at the end of the year. During the first year of production, the number of sea lice treatment interventions is typically low with a mean of 2.1 treatments per site-year.

A similar epidemiological pattern is seen in the second year of production. Adult lice counts are at negligible levels for the first half of the year but increase from week 26 onwards. The mean lice counts in the second year of production never exceed 5 lice per fish before peaking around week 33 and gradually falling off. During the second year of production L. salmonis abundance is generally higher requiring increased medicinal intervention and the mean number of treatments is 6.5 per site-year. Clearly $C$. elongatus adults have distinctively different patterns in the first and second six months of each year and the pattern consistently recurs irrespective of year of production. Moreover, adult $C$. elongatus counts appear to be strongly seasonal with adult numbers expanding promptly following the mid-summer equinox.

\section{Treatment}

When fish are in the first year of production, Figure 2a, site-years with few treatments are associated with low levels of lice infestation in the second half of the year. In the same period increased treatment levels are associated with higher levels of infestation. Regardless of whether as many as 3 or 5 treatments per annum are applied, the resultant sea lice levels remain much the same reaching peaks of between 5 and 10 lice per fish between weeks 30 and 40. Management practice is such that chemotherapeutic treatments are focused on controlling $L$. salmonis rather than $C$. elongatus. During the period under study the types of treatment used have altered substantially. In 1997 and 1998 the majority of treatments were by hydrogen peroxide with some dichlorvos. In 1999 cypermethrin began to be used on a wide scale and by 2000 accounted for most of the treatments used on the sites under study, with some additional use of Azamethiphos. It should also be noted that for 6 and 4 of the site-years, in their first and second years of production respectively, no treatment data were available. 
In contrast, in Figure 2b, the effect of treatment is shown for fish in the second year of production and adult lice levels are very similar irrespective of the intensities of treatments. Comparing Figures $2 \mathrm{a}$ and $2 \mathrm{~b}$ it is interesting to note that for fish receiving up to 5 treatments per annum the lice counts are higher by 2.6 lice per fish $(95 \% \mathrm{Cl} 1.4$ to 3.7$)$ at sites in the first year of production than those in the second year of production and this difference is highly significant $(p=0.0001, t$-test $)$. This is particularly salient since the first year production sites include as many as 15 out of 52 with one or no treatments and these have very low lice levels, unlike the second year production sites which have only 2 out of 40 with as few as one treatment.

\section{Annual abundance}

Table 1 lists summary mean weekly abundance levels for each of the years 1997 to 2000 . Since Figure 1 indicated distinctive patterns in each half of the year, these counts per fish are shown separately for January to June and July to December. These patterns are seen in more detail in Figures $3 a$ and $3 b$ where mean weekly abundances are shown for sites with fish in the first and second years of production respectively. In each of the four years, the adult $C$. elongatus levels on fish in the first year of production (Figure 3a) become markedly and rapidly elevated from week 26 onwards yet seldom exceed 10 lice per fish before falling off by the midwinter equinox. The highest $C$. elongatus adult levels are found between weeks 30 and 36, although for 1998 and 1999 levels remained persistently high until week 44.

Once again, for fish in the second year of production (Figure 3b), consistent seasonal patterns amongst years 1997 to 2000 are seen. The same distinctive rise takes place immediately after the midyear point, although the abundances attained for each year are lower than those seen for fish in the first year of production. The pattern for 1999 was anomalous as adult lice levels did not manage to sustain high levels once the rise was initiated and levels fell back abruptly until the end of the year.

Some of the undulating pattern seen for each of the years with both fish in the first and second year of production may arise from treatment interventions. However, in contrast to patterns reported for L. salmonis (Revie et al. 2002) the percentage difference between peaks 
and troughs is seldom high, indicating that treatment has a less disruptive effect on $C$. elongatus populations.

The overall summary of yearly infestations in Table 1, illustrates the consistency of $C$. elongatus patterns from season to season and from year to year. When compared to the first six month period of a year it can be seen that the counts typically increase three-fold for fish in the first year of production and almost double for fish in the second year of production in the second six month period. Analysing weekly levels for the first six months of the year indicates a small difference of 0.2 lice per fish $(95 \% \mathrm{Cl} 0.03$ to 0.4$)$ between fish in the first and second year of production, which is significant $(\mathrm{p}=0.02$, $\mathrm{t}$-test). In the second six month period the weekly levels observed in site-years in their first year of production are higher by 2.6 lice per fish $(95 \% \mathrm{Cl} 1.6$ to 3.6$)$ than those in the second year which is highly significant $(p=0.00002, t$ test $)$.

\section{Correlation}

It has been commented that $C$. elongatus has a more consistent and distinctive pattern of seasonal abundance in both the first and second years of production than is the case for $L$. salmonis. In addition when the relationship between the intensities of the two species is examined in detail there is strong evidence of abundances being inversely correlated. Consequently, when mean levels of $C$. elongatus are high on fish, the levels of $L$. salmonis are found to be low. This can be seen from Figure 4 where for the second half of each of the first and second production years the adult mean weekly abundance of $C$. elongatus is plotted against the mean weekly abundance of $L$. salmonis mobiles for the 36 site-years in which 3 to 5 treatments were administered. In the first year of production, C. elongatus counts are typically high while the corresponding L. salmonis counts are low. In contrast in the second year of production, when $L$. salmonis counts are high, the abundances of $C$. elongatus are low. The correlation coefficient between the abundance of $C$. elongatus and the reciprocal of the abundance of $L$. salmonis is $0.39(p=0.018)$ with $95 \%$ confidence interval from $(0.07,0.71)$ indicating a significant inverse relationship in the mean abundance of the two species. 


\section{Discussion}

The pattern of $C$. elongatus infestation on farmed salmon in Scotland is highly seasonal with the same distinctive pattern each year. Overall levels of mean abundance seldom exceed 9 adult sea lice per fish which is low compared to L. salmonis, where mean abundance levels in the second year of production can exceed 20 adult sea lice per fish (Revie et al. 2002).

In the first year of production, C. elongatus abundance is low between January and June, followed by a consistent steep increase in July which peaks in August and September before abundance drops steadily during October. This agrees with the pattern observed on two sites for a single year class by Bron et al. (1993) but is different to that reported by Wootten et al. (1982), who noted a much later period of peak infestation, in early November. The pattern seen here is also consistent with that suggested by Grant \& Treasurer (1993) and reported more fully in Treasurer (1998). C. elongatus were either absent or present in very low numbers during winter months both in recent clinical trials relating to the efficacy of emamectin benzoate (Stone et al. 2000a,b) and in an automatic-feed trial (Lyndon and Toovey 2000). The explanation for the distinctive pattern of growth in $C$. elongatus infestation in July on Scottish farms may well be environmental with the arrival of significant numbers of wild teleosts being suggested as the most likely cause by a number of authors (Wootten el al. 1982, Bron et al. 1993a/b, Wallace 1998, and Jackson et al. 2000).

The Scottish pattern would appear to differ from the situation reported elsewhere and in particular in Ireland. In an early study which looked at infestations on a farm with untreated salmon Tully (1989) also found a peak of infestation at around 8 adult lice per fish in midAugust with a fall off in September. However, he then found a subsequent rise to a mean of around 5 lice per fish in mid-October which remained high until the end of the year. In a later study (Minchin \& Jackson 1993) involving Irish farms using medicinal treatments the pattern was more akin to that seen in the data reported here though the peak level of infestation was reached in late June and had fallen to near-zero levels by late August. More recently Jackson, Deady, Hassett \& Leahy (2000) also published data from Ireland showing sporadic infestation patterns with peaks equally likely throughout the year. In a limited study in Norway, involving a single farm site over two years, Wallace (1998) observed that C. elongatus 
infestations were largely restricted to summer and autumn although in one year no adult $C$. elongatus were observed. Another Norwegian study focusing on wild sea trout found that infestations were seasonal with an increase in mean intensity in the late spring and a decline in the winter (Schram, Knutsen, Heuch \& Mo 1998). Finally, a study by Piasecki (1993) suggested a pattern for Caligus populations in North America almost identical to that reported here for fish in the first year of production, except that the rapid expansion of the population was reported to occur in June rather than in July.

In the first year of the production cycle for the Scottish situation reported here those sites receiving low, medium and high intensities of treatment are associated with different levels of infestation. While the overall pattern is similar it is clear that sites receiving one or no treatments exhibit the lowest level of infestation between July and November. The annual pattern is qualitatively similar in the second production year to the first except that during the peak period much lower levels of infestation are observed in the second year. Levels of $C$. elongatus are similar at the start of each of the two production years. This is despite the fact that the first year of the production cycle will normally be preceded by a fallowing period, while no such period occurs in the second year. Furthermore for sites with similar levels of treatment, the level of infestation observed for the second half of the first production year is significantly higher than for the same period in the second production year. This would strongly indicate that fallowing has no observable effect on $C$. elongatus levels. This concurs with Bron et al. (1993a) and Treasurer (1998) who both noted that fallowing appeared to have little effect on $C$. elongatus levels of infestation.

The observation that abundances of $L$. salmonis and $C$. elongatus appear to be inversely correlated may have several explanations. It is known that more treatments are administered in the second year when levels of $L$. salmonis in Scotland are demonstrably higher than those seen in the first year (Revie et al. 2002). It may be the case that $C$. elongatus adult lice are more sensitive to treatment. However, the analysis carried out has attempted to match siteyears with similar levels of treatment intervention in the first and second years. Given the seasonal nature of $C$. elongatus infestations the specific timing of treatments may be critical and additional analyses is being carried out to explore treatment timing effects. Alternative 
explanations must also be considered, such as the possibility that the developmental biology of the two species proceeds at different rates over the two-year production cycle or that $C$. elongatus have a feeding preference for fish in the first year of production. The specific hypothesis that the two species are in competition for fish and that as one species increases its abundance the other species decreases should not be discounted, despite the fact that Pike and Wadsworth (1999) noted that there was "little evidence for this possibility". An understanding of the cause(s) of this phenomenon may be important as strategic treatment, which focuses predominantly on controlling L. salmonis (Wadsworth, Grant \& Treasurer 1998, Rae 1999), may be less effective overall should $C$. elongatus be able to take advantage of the situation (Treasurer \& Grant 1994). Specifically with the recent introduction of emamectin benzoate, and its reported effectiveness in controlling L. salmonis (Stone et al. 2000a,b), it will be increasingly important for any effects on the abundance of $C$. elongatus to be kept under review.

In summary, the pattern of $C$. elongatus infestations on Atlantic salmon found on commercial farms in Scotland has a consistent and distinctive pattern. In July of the first production year there is a marked increase in population numbers before counts diminish towards the end of the first year. A similar epidemiological pattern recurs in the second year of production, except that counts of $C$. elongatus never attain the levels reached in the first year. There is clear evidence of population numbers being affected by chemotherapeutic treatments principally applied to control L. salmonis which is considered to be the major species significant to fish health. However, this alone does not explain the pattern of abundance nor why $C$. elongatus is high in the first year compared to the second, while the reverse is true for $L$. salmonis. $C$. elongatus is clearly an important species which needs to be better understood in relation to chemotherapeutic control and its environment. 


\section{References}

Bristow, G. A. \& Berland, B. (1991) A report on some metazoan parasites of wild marine salmon (Salmo salar L.) From the west coast of Norway with comments on their interactions with farmed salmon. Aquaculture 98, 311-318.

Bron, J. E., Sommerville, C., Wootten, R., \& Rae, G. H. (1993a) Fallowing of marine Atlantic salmon, Salmo salar L., farms as a method for the control of sea lice, Lepeophtheirus salmonis (Kroyer, 1837). Journal of Fish Diseases 16, 487-493.

Bron, J. E., Sommerville, C., Wootten, R., \& Rae, G. H. (1993b) Influence of treatment with dichlorvos on the epidemiology of Lepeophtheirus salmonis (Krøyer, 1837) and Caligus elongatus (Nordmann, 1832) on Scottish salmon farms. In: Pathogens of wild and farmed fish: sea lice (eds. G. A. Boxshall \& D. Defaye). Ellis Horwood Ltd, Chichester, UK, pp 263-274.

Bruno, D. W. \& Stone, J. (1990) The role of saithe, Pollachius virens L., as a host for the sea lice, Lepeophtheirus salmonis Krøyer and Caligus elongatus Nordmann. Aquaculture 89, 201-207.

Bush, A. O., Lafferty, K. D., Lotz, J. M. \& Shostak, A. W. (1997) Parasitology meets ecology on its own terms: Margolis et al. revisited. Journal of Parasitology 83, 575-583.

Costelloe, M., Costelloe, J., O'Donohoe, G., Coghlan, N. \& O'Connor, B. (1999) A review of field studies of the salmon louse, Lepeophtheirus salmonis Krøyer, on the west coast of Ireland. Bulletin of European Association of Fish Pathologists 19, 260-264.

Grant, A. N. \& Treasurer, J. W. (1993) The effects of fallowing on caligid infestations on farmed atlantic salmon (Salmo salar L.) in Scotland. In: Pathogens of wild and farmed fish: sea lice (eds. G. A. Boxshall \& D. Defaye). Ellis Horwood Ltd, Chichester, UK, pp 255-260.

Hogans, W. E. \& Trudeau, D. J. (1989) Preliminary studies on the biology of sea lice, Caligus elongatus, Caligus curtus and Lepeophtheirus salmonis (Copepoda: Caligoida) parasitic on cage-cultured salmonids in the lower Bay of Fundy. Canadian Technical Report of Fisheries \& Aquatic Sciences No. 1715, iv + 14pp.

Jackson, D. \& Minchin, D. (1992) Aspects of the reproductive output of two caligid copepod species parasitic on cultivated salmon. Invertebrate Reproduction \& Development 22, 8790.

Jackson, D., Deady, S., Hassett, D. \& Leahy, Y. (2000) Caligus elongatus as parasites of farmed salmonids in Ireland. Contributions to Zoology 69, 65-70.

Johnson, S. C. \& Albright, L. J. (1991) Development, growth and survival of Lepeophtheirus salmonis (Copepoda: Caligidae) under laboratory conditions. Journal of the Marine Biological Association UK 71, 425-436. 
Kabata, Z. (1979) Parasitic Copepoda of British Fishes. The Ray Society, London, UK.

Karlsbakk, E., Otterlei, E., Hoie, H. \& Nylund, A (2001) Parasites of cultured cod (Gadus morhua) postlarvae fed natural zooplankton. Bulletin of the European Association of Fish Pathologists 21, 63-70.

Landsberg, J. H., Vermeer, G. K., Richards, S. A. \& Perry, N. (1991) Control of the parasitic copepod Caligus elongatus on pond-reared red drum. Journal of Aquatic Animal Health $\mathbf{3}$, 206-209.

Lyndon, A. R. \& Toovey, J. P. G. (2000) Does the Aquasmart feeding system reduce sea louse [Lepeophtheirus salmonis (Krøyer)] infestation on farmed Atlantic salmon (Salmo salar L.) in winter? Aquaculture Research 31, 843-847.

MacKenzie, K. \& Morrison, J. A. (1989) An unusually heavy infestation of herring (Clupea harengus L.) with the parasitic copepod Caligus elongatus Nordmann, 1832. Bulletin of the European Association of Fish Pathologists 9, 12-13.

Minchin, D. \& Jackson, D. (1993) Studies on Caligus elongatus infestations on farmed salmonids in Ireland. International Council for the Exploration of the Sea CM1993/F:13, 1-14.

Neilson, J. D., Perry, R.I., Scott, J. S., \& Valerio, P. (1987) Interactions of caligid ectoparasites and juvenile gadids on Georges bank. Marine Ecology-Progress Series 39, 221-232.

Piasecki, W. - 1993: Preliminary study on the population structure of Caligus elongatus and its dynamics in Brandy cove, New Brunswick. Proceedings of the First European Crustacean Conference Paris, August 31 - September 5, 1992 (abstracts). Editions du Muséum national d'Histoire naturelle, Paris

Piasecki, W. (1996) The developmental stages of Caligus elongatus von Nordmann, 1832 (Copepoda: Caligidae). Canadian Journal of Zoology 74, 1459-1478.

Pike, A. W. (1989) Sea lice - major pathogens of farmed Atlantic salmon. Parasitology Today 5, 291-297.

Pike, A. W. \& Wadsworth, S. L. (1999) Sealice on salmonids: their biology and control. Advances in Parasitology 44, 233-337.

Rae, G. H. (1999) Sea lice, medicines and a national strategy for control. Fish Veterinary Journal 3, 46-51.

Revie, C. W., Gettinby, G., Treasurer, J. W., Rae, G. H. \& Clark, N. (2002) Temporal, environmental and management factors influencing the epidemiological patterns of sea lice (Lepeophtheirus salmonis) infestations on farmed Atlantic salmon (Salmo salar L.) in Scotland. Pest Management Science 58, 576-584.

Ritchie, G. (1997) The host transfer ability of Lepeophtheirus salmonis (Copepoda: Caligidae) from farmed Atlantic salmon, Salmo salar L. Journal of Fish Diseases 20, 153-157. 
Schram, T. A, Knutsen, J. A., Heuch, P. A. \& Mo, T. A. (1998) Seasonal occurrence of Lepeophtheirus salmonis and Caligus elongatus (Copepoda: Caligidae) on sea trout (Salmo trutta), off southern Norway. ICES Journal of Marine Science 55, 163-175.

Shaw, R. \& Opitz, M. (1996). Abundance of the parasitic copepod Caligus elongatus on wild pollack near commercial salmonid net-pens. Journal of Aquatic Animal Health 8, 75-77.

Stone, J., Sutherland, I. H., Sommerville, C., Richards, R. H. \& Varma, K. J. (2000a) Field trials to evaluate the efficacy of emamectin benzoate in the control of sea lice, Lepeophtheirus salmonis (Krøyer) and Caligus elongatus Nordmann, infestations in Atlantic salmon Salmo salar L. Aquaculture 186, 205-219.

Stone, J., Sutherland, I. H., Sommerville, C., Richards, R. H. \& Varma, K. J. (2000b) Commercial trials using emamectin benzoate to control sea lice Lepeophtheirus salmonis infestations in Atlantic salmon Salmo salar. Disease of Aquatic Organisms 41, 141-149.

Stuart, R. (1990) Sea lice, a maritime perspective. Aquaculture Association of Canada Bulletin 1, 18-24.

Treasurer, J. W. (1998) Sea lice management methods in Scotland. Caligus Newletter 5, 8-12.

Treasurer, J. W. \& Grant, A. N. (1994) 'Second' louse species must not be ignored. Fish Farmer 17(4), 46-47.

Treasurer, J. W. \& Pope, J. A. (2000) Selection of host sample number and design of a monitoring programme for ectoparasitic sea lice (Copepoda: Caligidae) on farmed Atlantic Salmon. Aquaculture 187, 247-260.

Tucker, C. S., Sommerville, C. \& Wootten, R. (2000) The effect of temperature and salinity on the settlement and survival of copepodids of Lepeophtheirus salmonis (Krøyer, 1837) on Atlantic salmon, Salmo salar L. Journal of Fish Diseases 23, 309-320.

Tully, O. (1989) The succession of generations and growth of the caligid copepods Caligus elongatus and Lepeophtheirus salmonis parasitising farmed Atlantic salmon smolts (Salmo salar L.). Journal of the Marine Biological Association of the United Kingdom 69, 279-287.

Wadsworth, S. L., Grant, A. N. \& Treasurer, J. W. (1998) A strategic approach to lice control. Fish Farmer 21(2), 8-9.

Wallace, C. (1998) Possible causes of salmon lice Lepeophtheirus salmonis (Krøyer, 1837) infections on farmed Atlantic salmon, Salmo salar L., in a western Norwegian fjord-situated fish farm: Implications for the design of regional management strategies. Thesis Canditatus Scientiarum, University of Bergen, Norway.

Wootten, R., Smith, J. W. \& Needham, E. A. (1982) Aspects of the biology of the parasitic copepods Lepeophtheirus salmonis and Caligus elongatus on farmed salmonids, and their treatment. Proceedings of the Royal Society of Edinburgh B 81(3), 185-197. 


\section{Acknowledgements}

This work was funded by MAFF under the LINK Aquaculture programme (ENV 12) and by Scottish Quality Salmon. The industrial partner is Marine Harvest Ltd and thanks are due to their support staff, and in particular to Mr Graeme MacKenzie for providing access to extract much of the data. Additional insights and support were supplied by the company's regional health managers: Mrs Carol Cox, Mr Alasdair MacLennan, Mr Alasdair (Atchie) Morrison and Mr Chris Wallace. 


\section{List of Tables and Figures}

Table 1 Mean abundance of $C$. elongatus for site-years in the first and second years of their production cycle divided according to year. (Standard errors, number of site-years and number of fish sampled are also shown)

Figure 1 Mean weekly abundance of $C$. elongatus adults based on 58 and 44 site-years in the first and second years of their production respectively during the period 1997 to 2000 .

Figure 2a Mean weekly abundance of $C$. elongatus adults in the first year of production on 16 site-years receiving low intensity of treatment (one or less treatments), 18 site-years of medium treatment (two or less treatments) and 18 site-years with high intensity of treatment (up to five treatments).

Figure $\mathbf{2} \mathbf{b}$ Mean weekly abundance of $C$. elongatus adults in the second year of production on 17 site-years receiving low intensity of treatment (five treatments or less), 11 site-years of medium treatment (seven treatments or less) and 12 site-years of high intensity of treatment (up to eleven treatments).

Figure 3a Mean weekly abundance of $C$. elongatus adults in the first year of production for each of the years 1997 to 2000 .

Figure $\mathbf{3 b}$ Mean weekly abundance of $C$. elongatus adults in the second year of production for each of the years 1997 to 2000 .

Figure 4 Scatterplot of pairs of $L$. salmonis mobile and $C$. elongatus adult mean abundances averaged over the period from weeks 25 to 40 for those site-years receiving between 3 and 5 treatments in either the first or second years of production during the period 1997 to 2000. 
Table 1 Mean abundance of $C$ elongatus for site-years in the first and second years of their production cycle divided according to year. (Standard errors, number of site-years and number of fish sampled are also shown)

\begin{tabular}{|c|c|c|c|c|c|c|c|}
\hline \multirow{2}{*}{\multicolumn{2}{|c|}{\begin{tabular}{|l|} 
First year of \\
production cycle
\end{tabular}}} & \multicolumn{2}{|c|}{$\begin{array}{c}\text { Abundance } \\
\text { January to June }\end{array}$} & \multicolumn{2}{|c|}{$\begin{array}{c}\text { Abundance } \\
\text { July to December }\end{array}$} & \multirow{3}{*}{$\begin{array}{c}\text { Number of } \\
\text { site-years }\end{array}$} & \multirow{3}{*}{$\begin{array}{c}\text { Total number of } \\
\text { fish sampled } \\
8155\end{array}$} \\
\hline & & \multirow{2}{*}{$\begin{array}{c}\text { Mean } \\
1.0\end{array}$} & \multirow{2}{*}{$\begin{array}{l}\text { SE } \\
0.2\end{array}$} & \multirow{2}{*}{$\begin{array}{c}\text { Mean } \\
4.5\end{array}$} & \multirow{2}{*}{$\begin{array}{l}\text { SE } \\
0.6\end{array}$} & & \\
\hline Year: & 1997 & & & & & & \\
\hline & 1998 & 0.8 & 0.1 & 2.7 & 0.5 & 16 & 8440 \\
\hline & 1999 & 2.1 & 0.4 & 4.9 & 0.6 & 13 & 7725 \\
\hline & 2000 & 1.4 & 0.4 & 3.9 & 0.6 & 17 & 7770 \\
\hline & All & 1.3 & & 4.0 & & 58 & 32090 \\
\hline \multicolumn{2}{|c|}{$\begin{array}{l}\text { Second year of } \\
\text { production cycle }\end{array}$} & & & & & & \\
\hline \multirow{5}{*}{ Year: } & 1997 & 0.8 & 0.2 & 1.8 & 0.2 & 12 & 9315 \\
\hline & 1998 & 1.2 & 0.3 & 2.4 & 0.4 & 9 & 7155 \\
\hline & 1999 & 0.3 & 0.1 & 1.2 & 0.2 & 12 & 8180 \\
\hline & 2000 & 1.6 & 0.3 & 1.5 & 0.4 & 11 & 7420 \\
\hline & All & 1.0 & & 1.8 & & 44 & 32070 \\
\hline
\end{tabular}




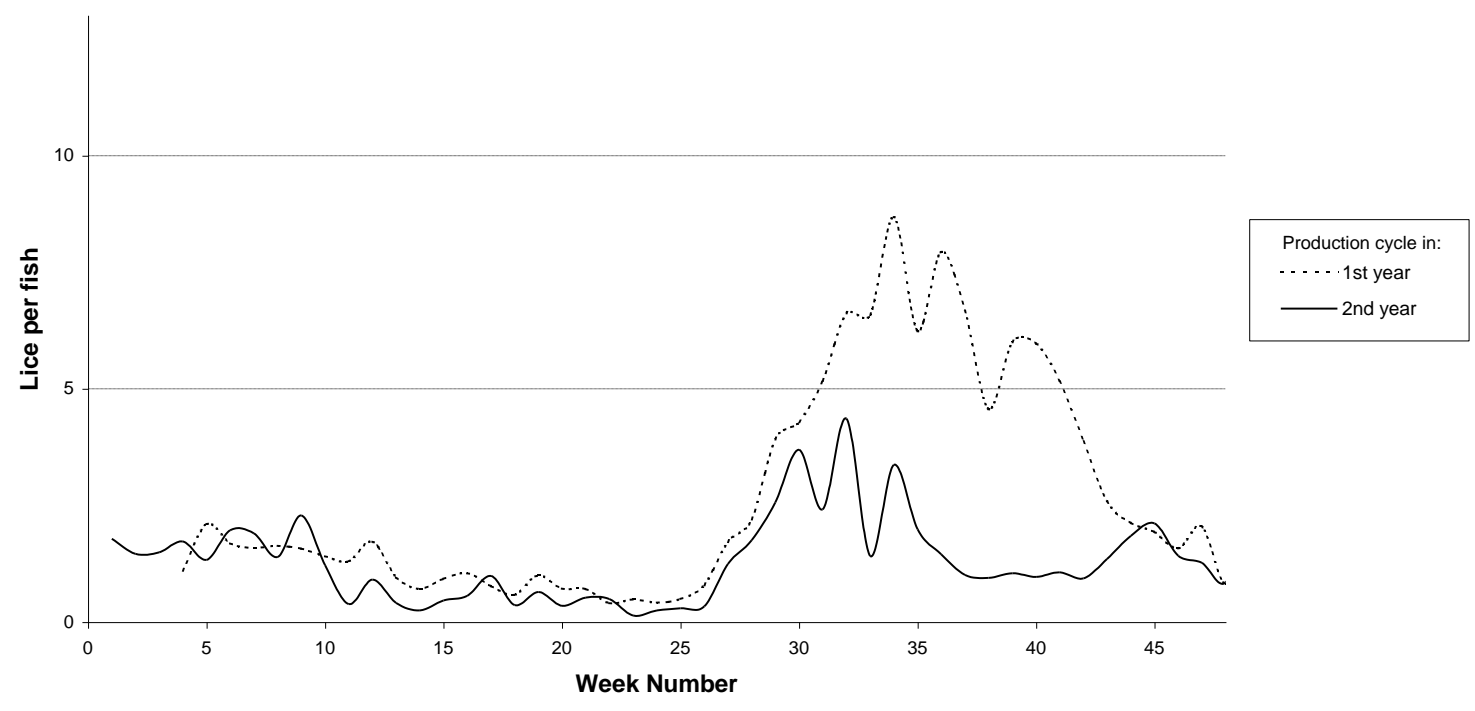

Figure 1 Mean weekly abundance of $C$. elongatus adults based on 58 and 44 site-years in the first and second years of their production respectively during the period 1997 to 2000. 


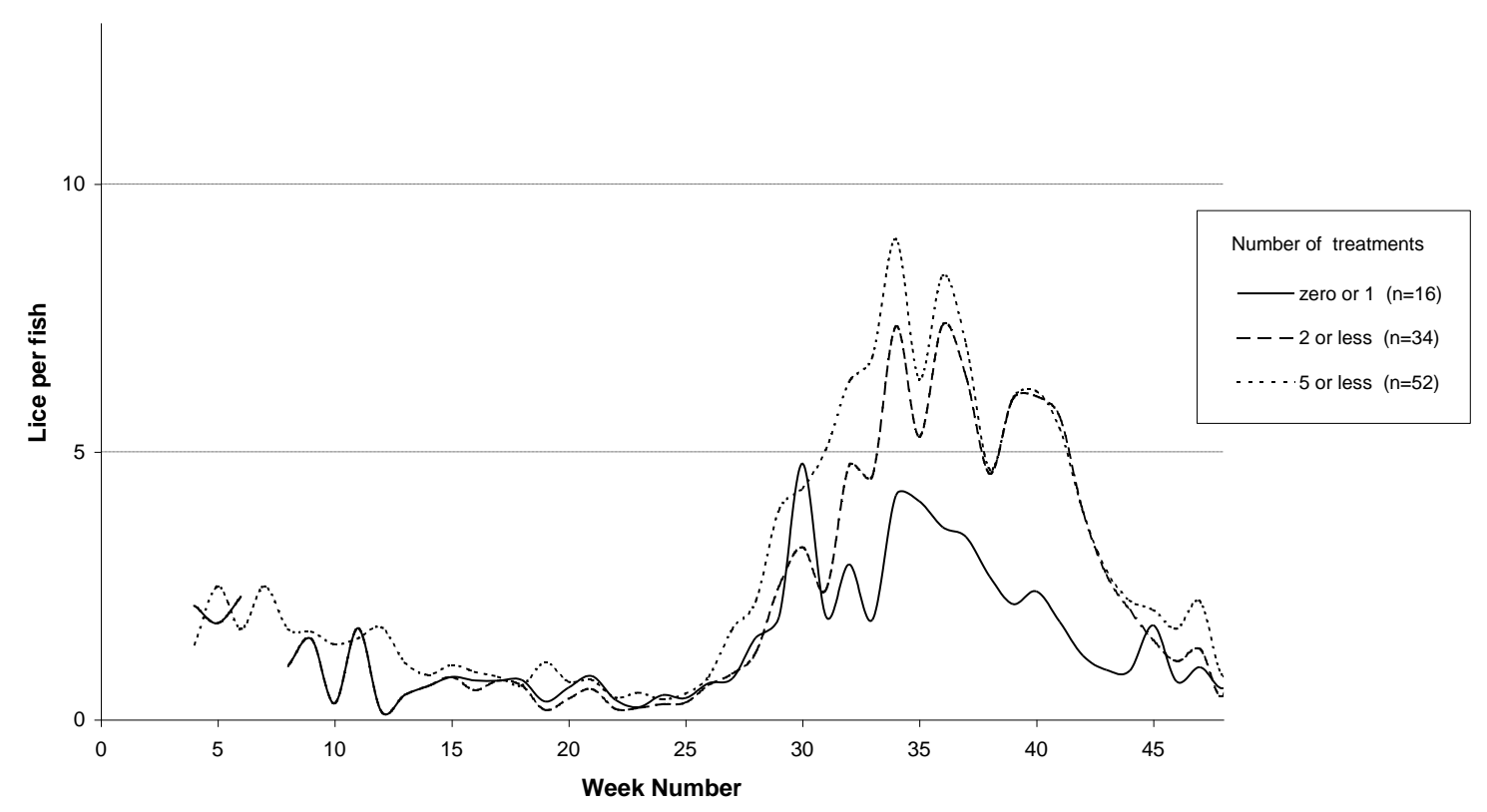

Figure 2a Mean weekly abundance of $C$. elongatus adults in the first year of production on 16 site-years receiving low intensity of treatment (one or less treatments), 18 site-years of medium treatment (two or less treatments) and 18 site-years with high intensity of treatment (up to five treatments). 


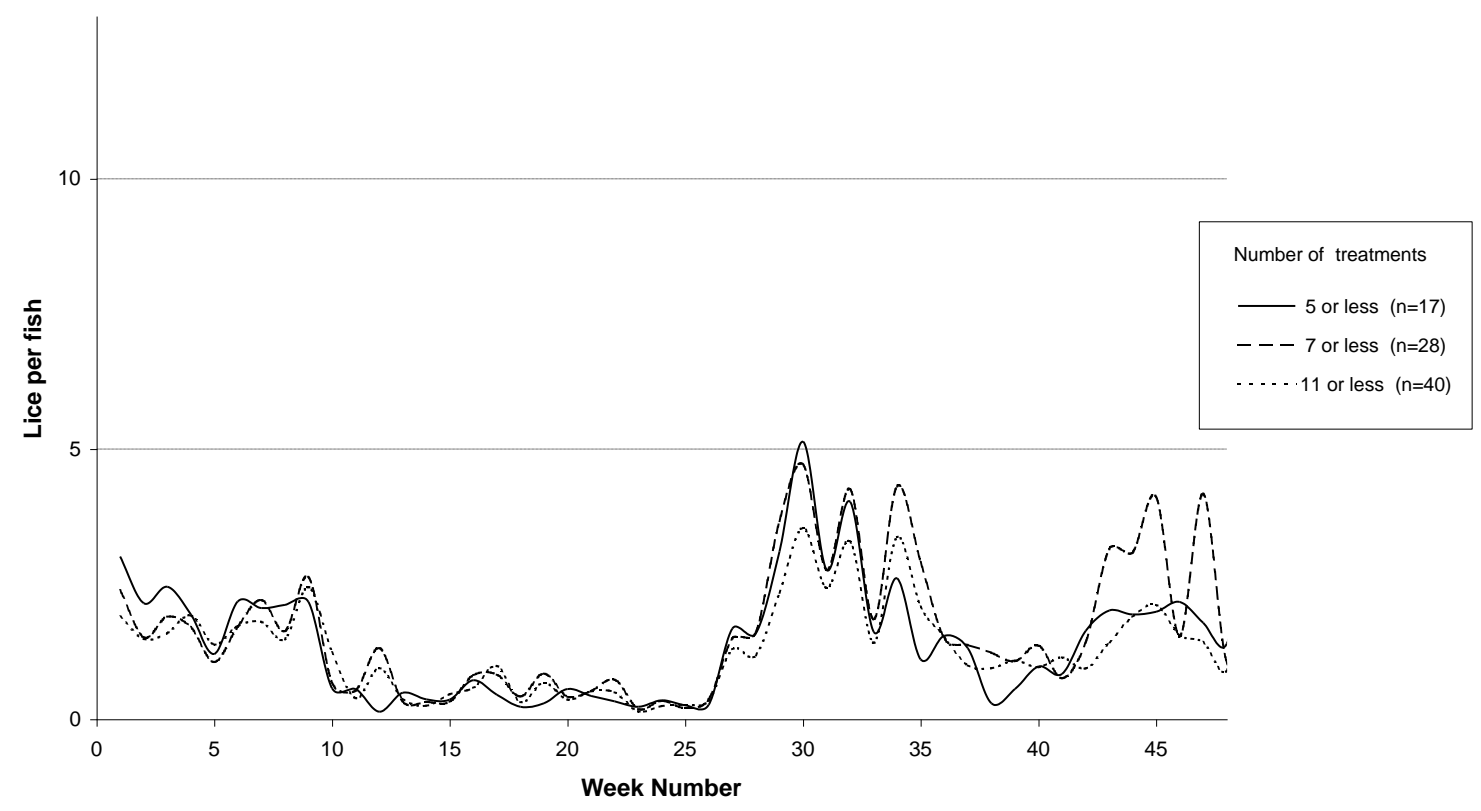

Figure $\mathbf{2 b}$ Mean weekly abundance of $C$. elongatus adults in the second year of production on 17 site-years receiving low intensity of treatment (five treatments or less), 11 site-years of medium treatment (seven treatments or less) and 12 site-years of high intensity of treatment (up to eleven treatments). 


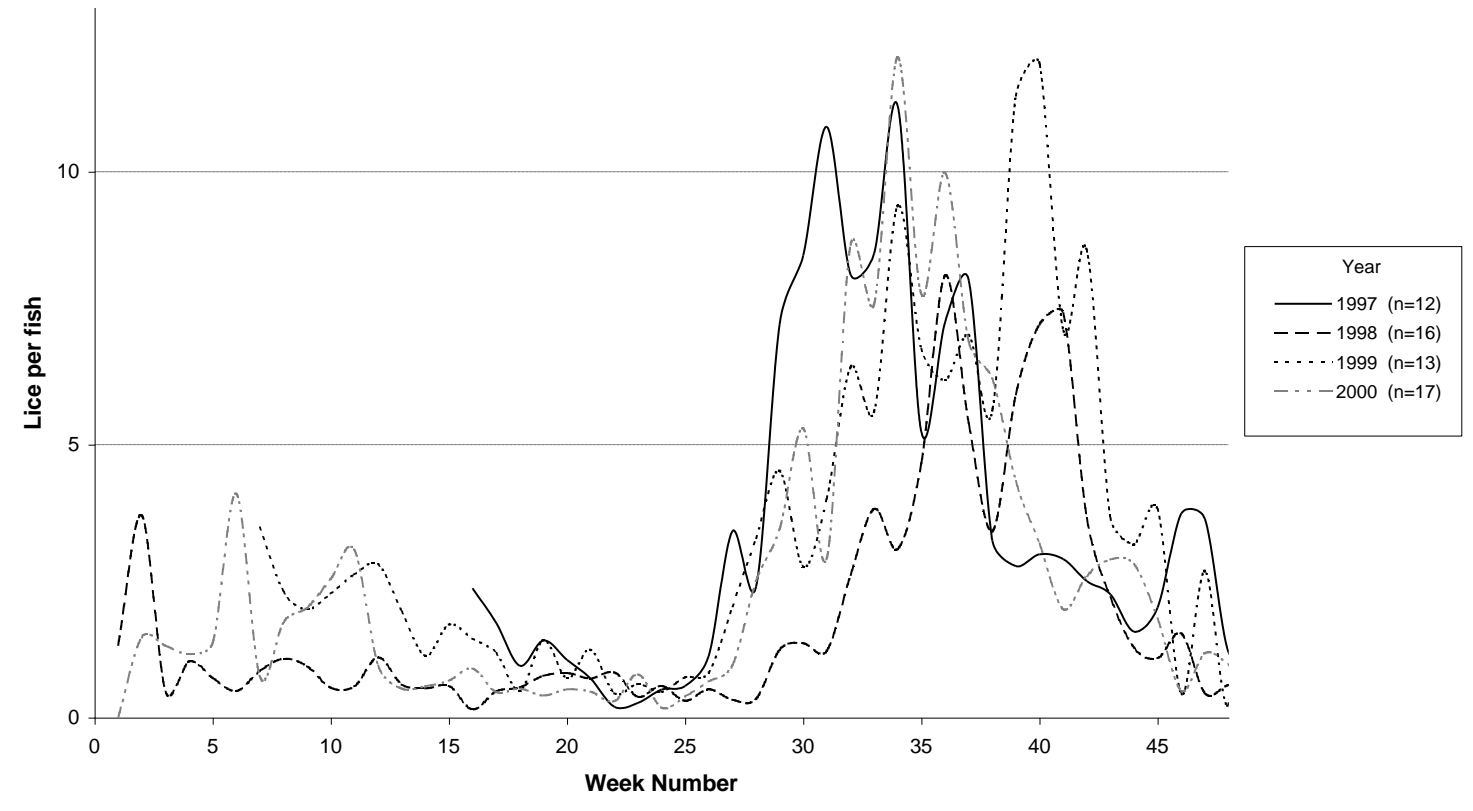

Figure 3a Mean weekly abundance of $C$. elongatus adults in the first year of production for each of the years 1997 to 2000 . 


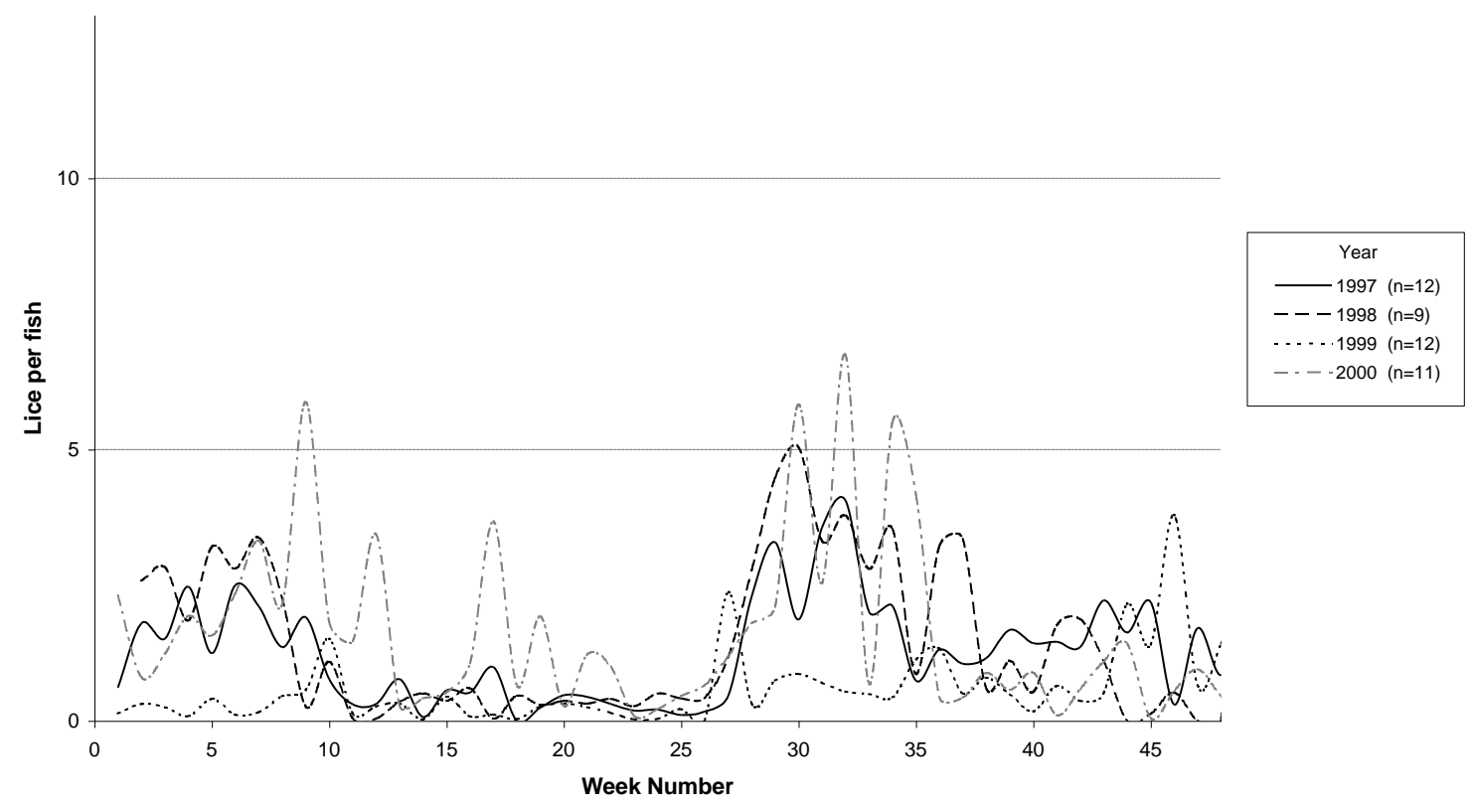

Figure $\mathbf{3 b}$ Mean weekly abundance of $C$. elongatus adults in the second year of production for each of the years 1997 to 2000 . 


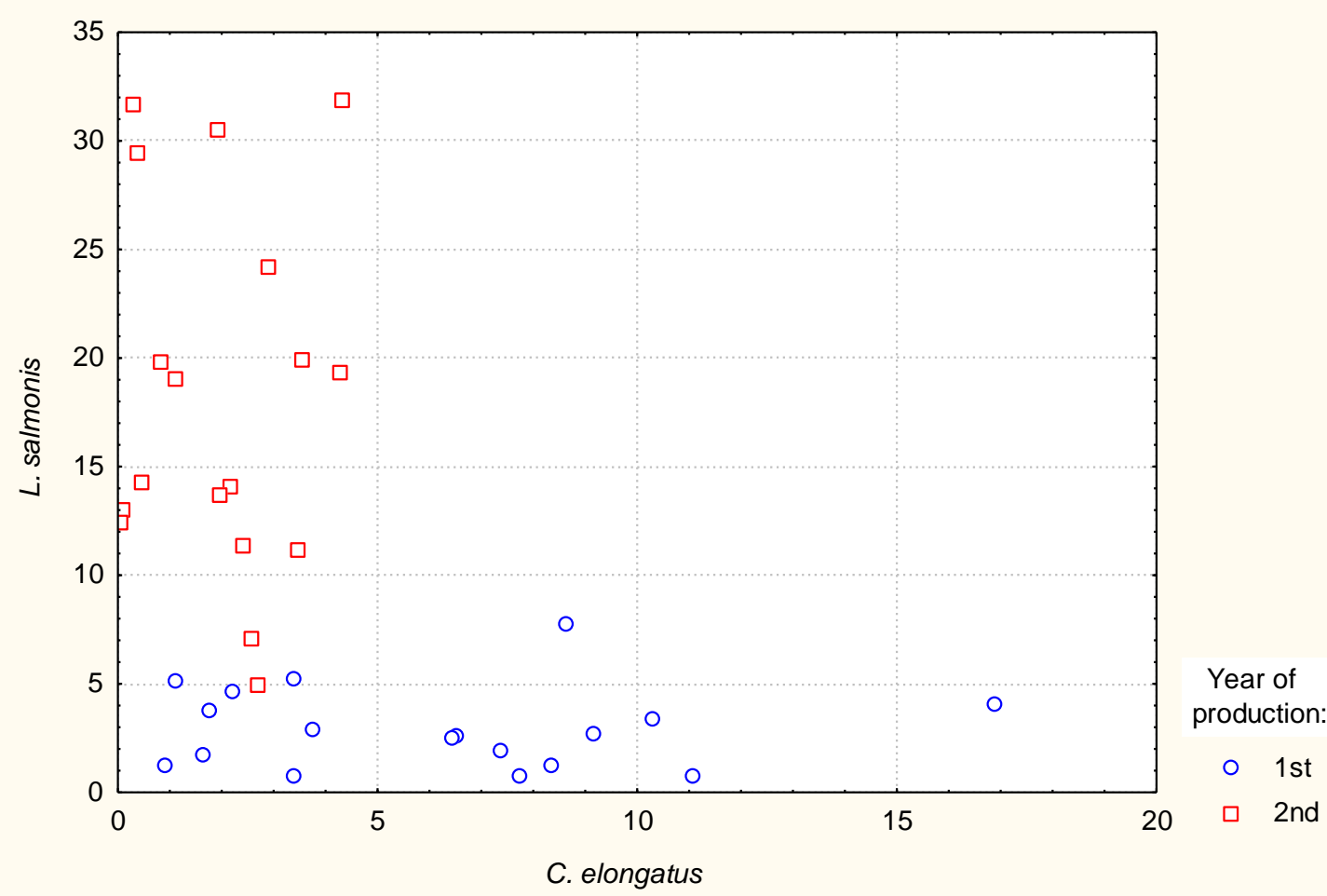

Figure 4 Scatterplot of pairs of $L$. salmonis mobile and $C$. elongatus adult mean abundances averaged over the period from weeks 25 to 40 for those site-years receiving between 3 and 5 treatments in either the first or second years of production during the period 1997 to 2000 . 